\title{
MÉTODOS DE INOCULAÇÃO DE Sclerotinia sclerotiorum EM SEMENTES DE FEIJÃO
}

Patricia Migliorini1, Gustavo Fonseca Rodrigues², Henrique Lopes Chagas², Raimunda Nonata Oliveira da Silva ${ }^{3}$, Lilian Vanussa Madruga de Tunes ${ }^{4}$

${ }^{1}$ Eng. Agrônoma, doutoranda do Programa de Pós Graduação em Ciência e Tecnologia de Sementes da Faculdade de Agronomia Eliseu Maciel (FAEM) da Universidade Federal De Pelotas (pati.migliorini@gmail.com)

2 Graduando de Agronomia da FAEL/UFPel

${ }^{3}$ Eng. Agrônoma, Mestranda do Programa de Pós Graduação em Ciência e Tecnologia de Sementes da Faculdade de Agronomia Eliseu Maciel (FAEM) da Universidade Federal De Pelotas

${ }^{3}$ Professora Doutora Eng. Agrônoma, do Programa de Pós Graduação em Ciência e Tecnologia de Sementes da Universidade Federal de Pelotas

Recebido em: 08/04/2016 - Aprovado em: 30/05/2016 - Publicado em: 20/06/2016 DOI: 10.18677/Enciclopedia_Biosfera_2016_068

RESUMO
O fungo Sclerotinia sclerotiorum (Lib.) Bary causador da doença conhecida como mofo branco, é um dos principais limitantes para o cultivo das culturas, principalmente pelo poder destrutivo que possui. Métodos de inoculação são importantes para avaliações de resistência de genótipos e de métodos de controle em fases iniciais do desenvolvimento de plântulas. Diante da necessidade de se obter sementes e plântulas infectadas, o presente trabalho teve por objetivo testar diferentes métodos de inoculação de Sclerotinia sclerotiorum em sementes de feijão e o impacto na emergência e desenvolvimento inicial das plântulas. Foram utilizadas sementes da cv. BRS Expedito, as quais foram inoculadas pelos métodos de suspensão de esporos, de contato com o patógeno em meio com restrição hídrica e inoculação do substrato com discos de BDA contendo micélio do fungo. $O$ delineamento experimental foi inteiramente casualizado com oito repetições. Foram feitas avaliações de emergência, comprimento de parte aérea, massa seca de parte aérea e incidência de sintomas da doença no hipocótilo e folha. Plântulas de feijão têm seu desempenho prejudicado pela associação de $S$. sclerotiorum através da inoculação das sementes. O método de contato o patógeno comprometeu a emergência e o desenvolvimento das plântulas, apresentando alta incidência de sintomas da doença.

PALAVRAS-CHAVE: Phaseolus vulgaris, podridão, plântulas.

\section{INOCULATION METHODS OF Sclerotinia sclerotiorum in SEED OF BEAN}

\begin{abstract}
The fungus Sclerotinia sclerotiorum (Lib.) Bary cause of the disease known as white mold, is one of the main limiting for the cultivation of crops, mainly by the destructive power it has. Inoculation methods are important for genotypes resistance evaluation and control methods in the early stages of seedling development. Faced with the need to obtain seeds and seedlings infected, this study aimed to test different methods of inoculation Sclerotinia sclerotiorum in bean seeds and the impact on the
\end{abstract}


emergence and early seedling development. hp seeds were used. Expedited BRS, which were inoculated by the methods spore suspension of the pathogen in contact with fluid restriction means and inoculation BDA discs containing mycelium and spores of the fungus on the substrate. The experimental design was completely randomized with eight repetitions. They were made emergency assessments, shoot length, dry weight of shoot and incidence of symptoms of the disease in hypocotyl and leaf. Bean seedlings have their performance impaired by Sclerotinea sclerotiorum association by inoculating seeds. The method of contacting the pathogen committed the emergence and seedling development, with high incidence of disease symptoms.

KEYWORDS: Phaseolus vulgaris, rot, seedlings

\section{INTRODUÇÃO}

O feijão (Phaseolus vulgaris L.) é uma planta pertencente à família das Leguminosae, que se destaca pela importância nutricional, social e econômica, sendo a principal fonte de proteínas para as populações de baixa renda. No Brasil estima-se que a área plantada de feijão em 2015/2016 chegue a 3.047,5 mil hectares, com produtividade média prevista de $1.086 \mathrm{Kg} / \mathrm{ha}$, resultando uma produção esperada de 3.309,3 mil de toneladas (CONAB, 2016).

A cultura está sujeita a um elevado número de doenças, sendo que os patógenos, são em sua maioria, transportados ou/e transmitidos por sementes. Entre as doenças da cultura está o "mofo branco" ou também chamado de "podridão de esclerotinia" ou "murcha de esclerotinia", causada pelo fungo Sclerotinia sclerotiorum. Os sintomas da doença podem ser vistos em hastes e ramos, inicialmente encharcados e consistência mole de coloração parda que se espalham rapidamente. Posteriormente, aparece crescimento micelial branco cotonoso que cresce sobre as superfícies aéreas infectadas. As partes doentes tornam secas, leves e quebradiças (BIANCHINI et al., 2005). As sementes podem ser infectadas e é nelas que o fungo constitui a principal via de disseminação a longas distâncias, podendo causar danos diretos, conseqüentemente reduzindo o potencial produtivo (BOTELHO et al., 2013).

Metodologias de inoculação são importantes para o desenvolvimento de pesquisas relacionadas a avaliação de resistência genética e desenvolvimento de métodos de controle (GARCIA et al., 2012; JUNGES et al., 2015). O método de inoculação deve garantir a reprodução e expressão dos sintomas típicos da doença nas plântulas ou plantas (SOUSA et al., 2008; FALCÃO et al., 2005). No entanto, os diferentes métodos de inoculação, tempo e temperatura podem apresentar respostas desiguais para cada cultura, e influenciar diretamente na infecção e desenvolvimento de sintomas e sinais do patógeno (ARAÚJO et al., 2006). Técnicas de inoculação devem garantir a infecção de sementes sem comprometer o potencial germinativo (SOUSA et al., 2008).

Os métodos utilizados para a inoculação em sementes podem ser realizados por meio da imersão das sementes em suspensão de esporos (SOUSA et al., 2008), contato da semente com a colônia fúngica desenvolvida tanto em meio de cultura batata-dextrose-ágar (BDA), ou/e com o emprego de condicionamento osmótico (VENTUROSO et al., 2015; REIS et al., 2014; BARROCAS et a., 2014; BOTELHO et al., 2013), ou também, pela contaminação do solo/substrato com discos de BDA contendo a colônia fúngica ou com grãos de cereais colonizados (FALCÃO et al., 2005). No entanto, nem sempre é possível atingir níveis satisfatórios de infecção, 
principalmente pelo fato da limitação de alguns testes terem de contaminar ou/e infectar a semente ou plântula.

Dessa forma, objetivou-se testar diferentes métodos de inoculação em sementes de feijão, capazes de proporcionar infecção por Sclerotinia sclerotiorum sem comprometer a viabilidade das sementes e estabelecimento das plântulas.

\section{MATERIAL E MÉTODOS}

Foram utilizadas sementes da cultivar BRS Expedito safra 2014/2015, com germinação de $82 \%$, previamente desinfestadas com álcool $70 \%$ e hipoclorito de sódio a $1 \%$ por um minuto. Posteriormente, conduziram-se três lavagens rápidas em água destilada. Por fim, esterilizou-se e secaram-se as sementes em condições de laboratório.

O fungo patogênico Sclerotinia sclerotiorum foi isolado a partir de escleródios coletados em lavoura de feijão, os quais foram submetidos à assepsia conforme relatado na desinfestação das sementes. Os isolados foram mantidos em ambiente estéril até a secagem sendo, a seguir, colocados sobre meio de cultura de BDA (batata-dextrose-ágar) e incubados a $20^{\circ} \mathrm{C} \pm 1^{\circ} \mathrm{C}$ e fotoperíodo de $12 / 12 \mathrm{~h}$ por sete dias. Posteriormente procedeu-se os seguintes métodos para testar a inoculação de S. sclerotiorum nas sementes, que foram constituídos de:

Método de contato com o patógeno em meio de cultura com restrição hídrica: Discos com $7 \mathrm{~mm}$ de diâmetro, contendo micélio do isolado, foram transferidos para placas de Petri de $9 \mathrm{~cm}$ contendo meio de cultura BDA modificado (restrição hídrica) com soluto de sacarose no potencial hídrico -0,6 MPa (REY et al., 2009). As placas foram colocadas em câmara crescimento por quinze dias a temperatura de $20^{\circ} \mathrm{C} \pm 1^{\circ} \mathrm{C}$ e com fotoperíodo de $12 \mathrm{~h}$.

Em cada placa que estavam completamente colonizadas pelo fungo foram depositadas trinta sementes de feijão, distribuídas em fileiras, levemente prensadas sobre o meio. As sementes foram retiradas após $48 \mathrm{~h}$ e postas para secar sobre papel filtro em temperatura ambiente.

Método com suspensão de micélio: $O$ fungo foi cultivado em meio BDA e incubado por 15 dias em câmara de crescimento com temperatura de $20{ }^{\circ} \mathrm{C} \pm 1^{\circ} \mathrm{C}$ e fotoperíodo de $12 \mathrm{~h}$. Após, adicionou-se $15 \mathrm{~mL}$ de água destilada e esterilizada por placa, e com auxílio de um pincel esterilizado, homogeneizou-se a massa de micélio. Em seguida, foi utilizada gaze para a retirada de impurezas, como meio de cultura ou pedaços da colônia. Para cada $40 \mathrm{~g}$ de sementes foram adicionados $10 \mathrm{~mL}$ da suspensão. As sementes permaneceram embebidas em suspensão por 5 minutos, quando houve drenagem do excedente de água e mantidas em ambiente estéril.

Inoculação do substrato com discos de BDA contendo micélio do fungo: Para infestação do substrato, cinco discos $(5 \mathrm{~mm})$ de micélio foram retirados de colônias cultivadas em meio BDA, mantidas em câmara de crescimento com temperatura de $20^{\circ} \mathrm{C} \pm 1^{\circ} \mathrm{C}$ e fotoperíodo de $12 \mathrm{~h}$ durante quinze dias. Os discos foram depositados em copos plásticos de $200 \mathrm{~mL}$ contendo substrato vermiculita autoclavada e previamente umedecida com água destilada e esterilizada, sendo posteriormente acondicionados em sacos plásticos devidamente fechados e levados para a câmara de crescimento por sete dias a temperatura de $2^{\circ} \mathrm{C} \pm 11^{\circ} \mathrm{C}$ e com fotoperíodo de $12 \mathrm{~h}$. 
Decorrido o procedimento de inoculação do substrato, e das sementes pelo método de contato direto e suspensão realizou-se a semeadura das sementes de feijão na profundidade de $2 \mathrm{~cm}$, em copos plásticos de $200 \mathrm{~mL}$ contendo substrato de vermiculita esterilizada. Para cada tratamento foram utilizadas 40 sementes, distribuídas em oito repetições. Os tratamentos contendo diferentes métodos de inoculação foram mantidos em câmara de crescimento com temperatura de $20{ }^{\circ} \mathrm{C} \pm$ $1^{\circ} \mathrm{C}$ e fotoperíodo de $12 \mathrm{~h}$, durante quinze dias. Para o tratamento testemunha (controle) utilizou-se sementes não inoculadas. A quantidade de água necessária foi realizada conforme a capacidade de campo.

Foram realizadas avaliações de:

Emergência - Avaliaram-se aos 10 (E10) e aos 15 (E15) dias após a semeadura (DAS), considerando-se plântulas emergidas aquelas com folíolos primários expandidos, e os resultados foram expressos em porcentagem.

Comprimento de parte aérea - Aos 10 (CPA10) e 15 (CPA15) DAS, plântulas normais de cada repetição foram avaliadas pela medida do início da parte aérea até o ápice da folha mais nova, mensurada com auxílio de uma régua graduada em centímetros, sendo os resultados expressos em cm/plântula.

Massa seca de parte aérea (MSPA) - Aos 15 DAS, a parte aérea de plântulas normais de cada repetição foram dispostas para secar em estufa regulada a $70 \stackrel{\circ}{ }$, até atingirem massa constante, obtido em 72 horas. Após estas foram pesadas e os resultados expressos em gramas/plântula.

Incidência de doença - a avaliação foi realizada aos 15 DAS. Foram observados sintomas no hipocótilo e em folha de todas as plântulas de cada repetição dos tratamentos, sendo os resultados expressos em porcentagem de incidência de sintomas em folhas (IF) e incidência no hipocótilo $(\mathrm{IH})$.

O delineamento experimental utilizado foi inteiramente casualizado, sendo constituído por quatro tratamentos e oito repetições. Os dados foram submetidos à análise de variância (ANOVA), e as médias dos tratamentos comparadas pelo teste de Tukey $(p \leq 0.05)$.

\section{RESULTADOS E DISCUSSÃo}

$\mathrm{Na}$ Tabela 1 observa-se que houve diferenças na emergência aos 10 e 15 dias após a semeadura de sementes de feijão submetidas a diferentes métodos de inoculação de Sclerotinia sclerotiorum.

TABELA 1. Emergência de plântulas de feijão aos 10 (E10) e 15 (E15) dias após a semeadura (DAS), comprimento de parte aérea aos 10 (CPA10) e 15 (CPA15) DAS e massa seca de parte aérea (MSPA), em função de diferentes métodos de inoculação de Sclerotinia sclerotiorum em sementes. Pelotas, 2016.

\begin{tabular}{|c|c|c|c|c|c|}
\hline Tratamento & E10 & E15 & $\begin{array}{l}\text { CPA10 } \\
--(\mathrm{cm}\end{array}$ & $\begin{array}{c}\text { CPA15 } \\
\text { tula)----- }\end{array}$ & $\begin{array}{c}\text { MSPA } \\
\text { (g/plântula }\end{array}$ \\
\hline Testemunha & $89 a$ & $93 a$ & $13,36 \mathrm{a}$ & $16,03 \mathrm{a}$ & $0,100 \mathrm{a}$ \\
\hline Contato & $47 \mathrm{~b}$ & $53 \mathrm{~b}$ & $5,48 \mathrm{c}$ & $6,32 \mathrm{c}$ & $0,054 \mathrm{~b}$ \\
\hline Disco & $83 a$ & $85 \mathrm{a}$ & $12,81 \mathrm{ab}$ & $13,71 \mathrm{ab}$ & $0,086 \mathrm{~b}$ \\
\hline Suspensão & $80 \mathrm{a}$ & $83 a$ & $11,22 \mathrm{~b}$ & $11,43 \mathrm{~b}$ & $0,086 \mathrm{~b}$ \\
\hline Média & 74,43 & 78,33 & 10,71 & 11,87 & 0,081 \\
\hline CV(\%) & 13,29 & 11,79 & 13,95 & 14,29 & 22,46 \\
\hline
\end{tabular}

*Médias seguidas pela mesma letra minúscula na coluna, não diferem entre si, a $5 \%$ de probabilidade pelo teste de Tukey. ${ }^{\text {ns }}$ :não significativo. Testemunha: sementes não inoculadas; Contato: método de contato com o patógeno em meio de cultura BDA com restrição hídrica; Suspensão: método com suspensão de micélio; Disco: inoculação do substrato com discos de BDA contendo micélio do fungo.

ENCICLOPÉDIA BIOSFERA, Centro Científico Conhecer - Goiânia, v.13 n.23; p. $797 \quad 2016$ 
O método de contato com o patógeno causou redução na emergência de plântulas nos dois períodos de avaliação, apresentando porcentagens de 47 e 53 \% para emergência aos 10 e 15 DAS, respectivamente. REIS et al. (2014), avaliando a inoculação artificial de $S$. sclerotiorum em soja, observaram índices de emergências entre 20 e $43 \%$ em meios de com e sem restrição hídrica. Em culturas oleaginosas, a emergência das plântulas teve uma redução superior a 60\% (VENTUROSO et al., 2015).

Os demais métodos de inoculação não diferiram da testemunha durante a emergência das plântulas, sendo encontrado valores superiores a $80 \%$. Este resultado pode ser decorrente de que quanto menor o nível de potencial de inóculo do patógeno, menor a morte das sementes. FALCÃO et al. (2005) também não encontraram efeito na mortalidade de plântulas de soja para $S$. sclerotiorum e Sclerotium rolfsii por meio do método de contaminação do solo por meio de discos de micélio.

A partir dos valores obtidos para comprimento de parte aérea aos 10 e 15 dias após a semeadura e massa de matéria seca de parte aérea, pode ser observado que o patógeno influenciou negativamente o desenvolvimento das plântulas de feijão em comparação com a testemunha não inoculada (Tabela 1). BOTELHO et al. (2013) observaram que independente do nível do inóculo inicial de $S$. sclerotiorum, danos acentuados podem ser vistos no vigor e germinação de sementes de feijão.

Confirmando os resultados da emergência, o método de contato com o fungo, comprometeu também o desenvolvimento das plântulas, seguidas pelo método de suspensão de micélio, onde houve a geração de plântulas menos vigorosas e confirmando os efeitos prejudiciais do patógeno. VENTUROSO et al. (2015) comentam que a agressividade da $S$. sclerotiorum está associada as condições ambientais ideais para o desenvolvimento do patógeno e da gama de hospedeiros suscetíveis que esse fungo ataca.

Independente do método de inoculação, sementes contaminadas ou infectadas pelo patógeno produziram plântulas com menor conteúdo de massa de matéria seca de parte aérea (Tabela 1). Esses resultados colaboram com diversos autores e confirmam o efeito prejudicial do fungo sobre o desempenho inicial das culturas (BOTELHO et al., 2013; REIS et al., 2014; VENTUROSO et al., 2015).

Diferentes meios de inoculação vêm sendo utilizados para possibilitar a infecção de sementes com diferentes níveis de inóculo, capazes de influenciar a germinação das sementes e na taxa de transmissão de patógenos (SOUSA et al., 2008; REIS et al., 2014; VENTUROSO et al., 2015). Porém, o método de inoculação precisa da boa germinação de sementes e emergência de plântulas e ainda que garantam níveis de infecção satisfatórios para posterior utilização nos trabalhos (SOUSA et al., 2008).

As diferentes técnicas de inoculação de $S$. sclerotiorum em sementes de feijão apresentaram alta incidência de sintomas da doença (Tabela 2). Observaramse sintomas em todas as plântulas do tratamento em que as sementes foram expostas ao método de contato com o patógeno por $48 \mathrm{~h}$. Houve sintomas tanto no hipocótilo como em folha e diferindo significativamente dos de mais tratamentos.

Para REIS et al. (2014) quanto maior o nível de potencial de inóculo determinado pela exposição da semente ao patógeno, menor é a emergência das plântulas, maior número de sementes mortas e maior o nível de transmissão do fungo em sementes de soja. Em oleaginosas, essa transmissão para as plântulas 
também foi verificada por VENTUROSO et al. (2015), o que relata que $S$. sclerotiorum é um patógeno muito agressivo, devido à rápida colonização do tecido vegetal e causar morte das plantas.

TABELA 2. Incidência de sintomas da doença no hipocótilo (IH) e incidência de sintomas na folha (IF) em função de diferentes métodos de inoculação de Sclerotinia sclerotiorum em sementes. Pelotas, 2016.

\begin{tabular}{lll}
\hline Tratamento & IH (\%) & IF (\%) \\
\hline Testemunha & $0 \mathrm{a}$ & $0 \mathrm{a}$ \\
Contato & $100 \mathrm{c}$ & $100 \mathrm{c}$ \\
Disco & $78 \mathrm{~b}$ & $37 \mathrm{~b}$ \\
Suspensão & $84 \mathrm{bc}$ & $50 \mathrm{~b}$ \\
\hline CV (\%) & 12.31 & 20.03 \\
\hline
\end{tabular}

${ }^{*}$ Médias seguidas pela mesma letra minúscula na coluna, não diferem entre si, a $5 \%$ de probabilidade pelo teste de Tukey. ${ }^{\text {ns: }}$ :não significativo. Testemunha: sementes não inoculadas; Contato: método de contato com o patógeno em meio de cultura BDA com restrição hídrica; Suspensão: método com suspensão de micélio; Disco: inoculação do substrato com discos de BDA contendo micélio do fungo.

A incidência de sintomas no hipocótilo variou de 78,84 e 100\%, e para folha porcentagens de 37, 50 e 100\% para os métodos de inoculação das sementes por meio de discos, suspensão e de contato, respectivamente. Resultados esses que discordam dos encontrados por FALCÃO et al. (2005), que observaram respostas insatisfatórias em termos de incidência de doença em soja causada por Sclerotinea sclerotiorum e Sclerotium rolfsii por meio da utilização do método de inoculação por discos de meio BDA com micélio para a contaminação do solo.

O fungo provocou sintomas típicos de apodrecimento em plântulas de feijão, com lesões encharcadas que rapidamente se espalharam para hastes e ramos. Nas folhas foram observados sintomas reflexos de murcha e amarelecimento, seguido de queda prematura das folhas e morte das plântulas.

Os resultados do trabalho demonstram que a inoculação do patógeno em sementes de feijão sobre diferentes formas de contaminação pode comprometer a emergência e o desenvolvimento de plântulas. No entanto, devem-se levar em consideração os princípios da fitopatologia: ambiente favorável, patógeno virulento, e genótipo suscetível. Assim, se faz necessário mais estudos a fim de obter seleções mais criteriosas para formas de inoculação em mais genótipos de feijão.

\section{CONCLUSÃO}

Plântulas de feijão têm seu desempenho prejudicado pela associação de Sclerotinea sclerotiorum por meio da inoculação das sementes.

O método de inoculação das sementes de feijão por meio da técnica de contato com o patógeno apresenta alta incidência de doença, comprometendo o desenvolvimento das plântuas.

\section{REFERÊNCIAS}

ARAÚJO, D.V.; POZZA, E.A.; MACHADO, J.C.; ZAMBENEDETTI, E.B.; CELANO, F.A.O.; CARVALHO, E.M.; CAMARGOS, V.N. Influência da temperatura e do tempo de inoculação das sementes de algodão na transmissibilidade de Colletotrichum 
gossypii var. cephalosporioides. Fitopatologia Brasileira, v. 31, n. 1, p. 35-40, 2006. Disponível em: <http://www.scielo.br/pdf/fb/v31n1/a06v31n1>

BARROCAS, E.N.; MACHADO, J.C.; ALVES, M.C.; CORRÊA, C.L. Desempenho de sementes de algodão submetidas à deficiência hídrica e presença de Colletotrichum gossypii var. cephalosporioides. Bioscience Journal, v. 30, n. 2, p. 421-428, 2014.

BIANCHINI, A., MARINGONI, A.C.; CARNEIRO, S.M.P.G. Doenças do feijoeiro (Phaseoluls vulgaris L.). In: KIMATI, H., AMORIM, L., REZENDE, J.A.M., BERGAMIN FILHO, A.; CAMARGO, L.E.A. (Eds.) Manual de Fitopatologia. v.2, 4 ed. São Paulo. Editora Ceres. 2005. P. 333-349.

BOTELHO, L.S.; ZANCAN, W.L.A.; MACHADO, J.C.; BARROCAS, E.N. Performance of common bean seeds infected by the fungus Sclerotinia sclerotiorum. Journal of Seed Science, v.35, n.2, p.153-160, 2013. Disponível em: <http://dx.doi.org/10.1590/S2317-15372013000200003> doi: 10.1590/S231715372013000200003.

CONAB - Companhia nacional de abastecimento. Acompanhamento da safra brasileira de grãos, v. 3 - Safra 2015/16, n. 7 - Sétimo levantamento Levantamento, Abril $2016 . \quad$ Disponível em: http://www.conab.gov.br/OlalaCMS/uploads/arquivos/16_04_07_09_04_20_boletim_ graos_abril_2016_-_final.pdf. Acesso em: 06/04/2016.

FALCÃO, J. V.; ORILI, F. P.; ÁVILA, Z. R. de; MELLO, S. C. M. de. Estabelecimento de metodologia para contaminação de solo com propágulos dos fungos Sclerotinia sclerotiorum e Sclerotium rolfsii, e expressão de doença em soja. Comunicado Técnico. Brasília, 2005.2 Disponível em: http://ainfo.cnptia.embrapa.br/digital/bitstream/CENARGEN/27926/1/cot135.pdf

GARCIA, R.A.; JULIATTI, F.C. Avaliação da resistência da soja a Sclerotinia sclerotiorum em diferentes estádios fenológicos e períodos de exposição ao inóculo.Tropical Plant Pathology, v. 37, n. 3, p. 196-203, 2012. Disponível em: <http://dx.doi.org/10.1590/S1982-56762012000300006> doi: 10.1590/S198256762012000300006

JUNGES, E.; MUNIZ, M.F.B.; BASTOS, B.O.; ORUOSKI, P. Biopriming in bean seeds. Acta Agriculturae Scandinavica, Section B - Soil \& Plant Science. v. 66, p. 207-214, 2015. Disponível em: <http://dx.doi.org/10.1080/09064710.2015.1087585> doi:10.1080/09064710.2015.1087585.

REY, M.S.; LIMA, N.B.; SANTOS, J. Dos.; PIEROBOM, C.R. Transmissão sementeplântula de Colletotrichum Lindemuthinum em feijão (Phaseolus vulgaris). Arquivos do Instituto Biológico, v. 76, n. 3, p. 465-470. 2009.

REIS, G.F.; BACCHI, L.M.A.; GAVASSONI, W.L.; HIRATA, L. M.; PONTIM, B.C.A. Viabilidade de armazenamento de sementes de soja inoculadas com Sclerotinia sclerotiorum em meio com restrição hídrica. Summa phytopathologia, v. 40, n. 2, p. 
168-173, 2014. Disponível em: <http://dx.doi.org/10.1590/0100-5405/1908> doi: 10.1590/0100-5405/1908.

SOUSA, M.V.; MACHADO, J.C.; PFENNING, L.H.; KAWASAKI, V.H.; ARAÚJO, D.V.; SILVA, A.A.; MARTINI NETO, A. Métodos de inoculação e efeitos de Fusarium oxysporum f. sp. vasinfectum em sementes de algodoeiro. Tropical Plant Pathology, v. 33, n. 1, p.41-48, 2008. Disponível em: <http://dx.doi.org/10.1590/S1982-56762008000100007> doi: 10.1590/S198256762008000100007.

VENTUROSO, L.R.; BACCHI, L.M.A; GAVASSONI, W.L; VENTUROSO, L.A.C.; PONTIM, B.C.A; REIS, G.F. Inoculação de Sclerotinia sclerotiorum em sementes de oleaginosas: transmissão e seus efeitos sobre a emergência de plantas. Ciência Rural, v. 45, n. 5, p.788-793, 2015. Disponível em: <http://dx.doi.org/10.1590/01038478cr20140374> doi: 10.1590/0103-8478cr20140374. 